\title{
Configurações
}

Revista de sociologia

\section{Arte e comunidade em Esposende: uma abordagem de proximidade}

Art and community in Esposende: a proximity approach

Art et communauté à Esposende: une approche de proximité

\section{Teresa Mora e Ana Filipa Oliveira}

\section{(2) OpenEdition}

\section{Journals}

\section{Edição electrónica}

URL: http://journals.openedition.org/configuracoes/6335

DOI: $10.4000 /$ configuracoes. 6335

ISSN: 2182-7419

\section{Editora}

Centro de Investigação em Ciências Sociais

Edição impressa

Paginação: 50-69

ISSN: 1646-5075

\section{Refêrencia eletrónica}

Teresa Mora e Ana Filipa Oliveira, « Arte e comunidade em Esposende: uma abordagem de

proximidade », Configurações [Online], 22 | 2018, posto online no dia 11 fevereiro 2019, consultado o 30 abril 2019. URL : http://journals.openedition.org/configuracoes/6335; DOI : 10.4000/ configuracoes.6335 
Mora, Teresa; Oliveira; Ana Filipa - Arte e comunidade em Esposende: uma abordagem de proximidade. Configurações, vol. 22, 2019, pp. 50-69.

\title{
Arte e comunidade em Esposende: uma abordagem de proximidade $^{1}$
}

\author{
TERESA MORA* \\ Centro Interdisciplinar de Ciências Sociais - Universidade do Minho
}

ANA FILIPA OLIVEIRA**

\section{Resumo}

$\mathrm{O}$ artigo resulta de um estudo exploratório sobre o projeto de arte e comunidade AMAReMAR, desenvolvido na cidade costeira de Esposende, em 2016-2017, com a participação de residentes, a coordenação de artistas e o enquadramento de técnicos municipais. No lugar de investigadora-participante e tendo como principal contexto de ação a oficina de teatro, intentamos compreender como os artistas operam uma descolagem simbólica dos participantes-residentes dos dois bairros sociais de Esposende sul da categoria desvalorizadora da exclusão social.

Palavras-chave: arte e comunidade, exclusão social, descolagem simbólica.

\footnotetext{
Abstract

Art and community in Esposende: a proximity approach

The article is the result of a study regarding the AMAReMAR social art project, developed in the coastal city of Esposende, between 2016-2017. The project involves the participation of residents, the coordination of artists and the contextualisation of municipal technicians. In the role of research participant and having as main context of action the theatre workshop, we try to understand how artists produce a symbolic take off from a devaluated identity of social exclusion among the participants-residents of two social housing projects in South Esposende. Through this proximity approach,

*E-mail: tmora@ics.uminho.pt

**E-mail: anafilipinha14@hotmail.com

$1 \mathrm{O}$ material empírico e a pesquisa que servem de base à conceção deste artigo resultam do trabalho de investigação para finalização de mestrado desenvolvido por Ana Filipa Oliveira com a orientação de Teresa Mora. Assim, de cada vez que as autoras se referem a situações relativas à observação-participante da investigadora-mestranda, o uso da primeira pessoa do plural dá lugar à terceira pessoa do singular.
} 
we seek to contribute to a reflection on individual and collective added value of artistic creations within groups that possess any kind of fragile social position.

Keywords: art and community, social intervention, symbolic take off.

\section{Résumé}

Art et communauté à Esposende: une approche de proximité

Cet article est le résultat d'une étude concernant le projet d'art social AMAReMAR, qui s'est déroulé dans la ville côtière d'Esposende, entre 2016 et 2017. Ce projet a intégré la participation des résidents, la coordination des artistes et l'encadrement du personnel municipal. Depuis la perspective de chercheureuse-participante et ayant pour principal contexte d'action l'atelier de théâtre, nous avons essayé de comprendre comment les artistes produisent un décollage symbolique auprès des participants-résidents des deux quartiers sociaux du sud d'Esposende au niveau de la catégorie dévalorisante de l'exclusion sociale. A travers cette approche de proximité notre intention est de pouvoir contribuer à une réflexion sur la plus-value individuelle et collective des créations artistiques avec des groupes normativement identifiés à toute fragilité sociale.

Mots-clés: art et communauté, intervention sociale, décollage symbolique.

\section{Introdução}

Nas últimas décadas, no contexto internacional, principalmente a partir do final da década de 1980, as políticas públicas com incidência em práticas artísticas têm-se tornado cada vez mais frequentes. No caso da Europa e com o enquadramento de entidades supranacionais como o Conselho da Europa (CE), a Organização das Nações Unidas para a Educação, a Ciência e a Cultura (UNESCO) e a Organização para a Cooperação e Desenvolvimento Económico (OCDE), assiste-se à valorização política d' "o papel que a participação em atividade cultural e artística pode desempenhar no reforço das competências e das capacidades individuais e, especialmente, na qualificação e nos processos de aprendizagem das pessoas que integram sectores da população mais expostos a processos de exclusão ou isolamento social, cultural, cívico ou económico.” (Fortuna, 2014: 109-110). São recorrentes os enunciados discursivos (em particular sob a forma de recomendações aos Estados membros) que emanados do Conselho da Europa (cf. Fortuna, 2014:110-11) fazem da "cultura" e das "artes" os meios alternativos à prossecução dos chamados "objetivos sociais”. Grosso modo, tais enunciados compreendem o objetivo geral de prevenir ou atenuar os "problemas sociais" que são tradicionalmente perseguidos pelos serviços de ação social e, mais recentemente, por organizações do terceiro setor, nomeadamente aqueles associados à pobreza e à exclusão nas suas diversas variantes (Almeida et al, 1992; Costa, 1998; Diogo, Castro e Perista, 2015). 
A literatura científica que tem sido produzida sobre os efeitos sociais da participação de não-artistas em atividades artísticas é, também, já extensa (Matarasso, 1997; Guetzkow, 2002; Jermyn, 2001, 2004; Tiller, 2014, entre outros.). A par da importância económica conferida ao sector estratégico da cultura criativa, são discutidos os resultados individuais e coletivos conseguidos junto de pessoas e grupos cujos modos de vida ou condições de existência têm vindo a ser categorizados como estando de fora ou excluídos do modelo de sociedade vigente. Das muitas marcas sociais de fragilidade ou vulnerabilidade, considerem-se, a título de exemplo, as seguintes: desemprego, subsídio-dependência, reforma desprovida, minoria étnica carecida, isolamento, sem abrigo, reclusão prisional, internamento em centro educativo, educação especial, etc. .

No contexto português, de entre os principais programas de apoio a projetos de arte com objetivos sociais, é de destacar pela sua extensão, continuidade e envergadura o programa PARTIS - Práticas Artísticas para a Inclusão Social. Criado em 2013 pela Fundação Calouste Gulbenkian, o PARTIS, tal como se lê no site da Fundação, procura "tornar realidade a convicção (...) de que a arte é motor de inclusão e mudança social, pelo seu poder único de unir as pessoas" (Gulbenkian, 2017a). Trata-se de um programa de apoio financeiro a projetos que sendo provenientes, quer na primeira edição (2014-2016) quer na segunda (2016-2018), de diversas regiões do país, de norte a sul, e abarcando múltiplas linguagens artísticas (dança, vídeo, circo, música, fotografia e teatro) convergem entre si ao terem por denominador comum uma concepção da arte como meio de intervir socialmente "junto de grupos em situação de vulnerabilidade ou exclusão” (Gulbenkian, 2017a).

De entre muitos outros projetos financiados pelo PARTIS que poderiam aqui ser trazidos, refira-se, a título de exemplo, o projeto "Este Espaço que Habito", desenvolvido durante dois anos, de 2014 a 2016, pelo Movimento de Expressão Fotográfica (MEF), em parceria com o Ministério da Justiça. Este projeto PARTIS envolveu cerca de 200 jovens entre os 14 e os 20 anos de idade, em cumprimento de medida tutelar de internamento em seis centros educativos (na Guarda, no Porto, em Coimbra e em Lisboa). Por parte dos jovens intervenientes foram feitas câmaras pinhole e realizadas fotografias de exploração do centro e da cidade que habitam. O objetivo geral foi o de os "integrar pela fotografia” (MEF, 2017). Em concreto, procurou-se contribuir para a aquisição de competências sociais e de autoconhecimento através da criatividade e da exploração artística. O trabalho fotográfico desenvolvido veio a dar lugar à sua exposição pública em diversas modalidades: edição de um livro (Este espaço que habito, 2015), apresentação das imagens criadas em sucessivas exposições realizadas nas diversas cidades onde o projeto decorreu ${ }^{2}$, bem como um

2 Galeria de Arte do Paço da Cultura, Guarda, 3 a 21 de maio, 2017; Casa das Artes, Porto, 28 de maio a 28 de junho, 2016; Maria Pia Galeria, Lisboa, 8 a 30 de setembro, 2016; Sala da Cidade, Coimbra, 15 de outubro a 19 de novembro, 2016; Arquivo Municipal de Lisboa - Fotográfico, 11 de fevereiro a 25 de março, 2017 (MEF, 2017). 
documentário (cf. MEF, 2017). É ainda de destacar a reflexão que Matarasso (2017) dedicou a este projeto no seu blogue sobre a prática de arte comunitária em diversos países, incluindo Portugal.

Mais recentemente, para o período 2018-2022, o Programa Coesão e Integração Social (PGCIS), também de iniciativa da Fundação Calouste Gulbenkian e destinado igualmente a "grupos vulneráveis da população nomeadamente crianças e jovens em risco, idosos e comunidades migrantes”, vem reiterar a legitimidade das práticas artísticas na intervenção social, através de um dos seus três eixos estratégicos, o eixo direcionado para o apoio a organizações do terceiro setor, afirmando-as como "intervenções inovadoras" cujo desempenho em "processos de integração de grupos mais vulneráveis da população” é “cada vez mais reconhecido” (Gulbenkian, 2017b).

AMAReMAR, o caso sobre o qual este artigo se debruça, não sendo um projeto apoiado pela Fundação Calouste Gulbenkian, é certamente mais um exemplo de como a arte pode constituir-se em meio de intervenção social, designadamente na sua articulação com a "comunidade" como iremos clarificar na seção seguinte.

\section{AMAReMAR: um projeto de arte e comunidade}

Quando o termo "comunidade" surge associado à arte ("Arte e Comunidade"), estamos perante o quê? Nas artes comunitárias, independentemente da variedade de práticas artísticas, o processo de criação é concebido como processo coletivo de cariz participativo, com um grupo de não-artistas. $\mathrm{Na}$ maior parte das vezes, trata-se de um grupo constituído por "pessoas que têm em comum uma situação de desigualdade e de marginalidade” (Lamoureux, 2010: 5). As artes comunitárias implicam assim a existência ou a criação de um vínculo do artista com a comunidade, bem como uma forte sensibilidade ética (cf. Lamoureux, 2010: 5).

No caso do projeto AMAReMAR, o facto de Hugo Cruz, o seu consultor e coordenador artístico, ser simultaneamente o coordenador do Núcleo do Teatro do Oprimido do Porto e o encenador e diretor da PELE - Espaço de Contacto Social e Cultural, permite-nos encetar uma resposta à questão a partir do texto por meio do qual esta estrutura artística, criada no Porto, em 2007, sintetiza a experiência de cruzamento da arte com comunidade(s). No site da PELE (2017) lemos que uma das suas "principais áreas de trabalho" são os "projetos comunitários". No enunciado da sua apresentação, é-nos dito que qualquer projeto assim designado

é feito para a comunidade, pela comunidade e sobre a comunidade. É um teatro que é definido pelas pessoas que o integram. Parte da ideia de que todo ser humano tem o potencial criativo, o potencial que estimula gera não 
apenas transformações pessoais, mas também coletivas. O teatro (...) oferece um espaço (...) muito particular para que cada um de nós possa mostrar espontaneidade e autenticidade. (...). O processo criativo, construído, compartilhado, oferece às pessoas a oportunidade de redescobrir a sua narrativa, reescrever ou até encontrar outras formas de linguagem, tornando-se assim protagonistas dos processos que mudam. (PELE, 2017).

Compreende-se, pois, que estamos longe da figura concetual da comunidade na sua versão sociologicamente mais vulgarizada, isto é, a de um conceito que pela sua ênfase no coletivo acarreta um forte constrangimento do indivíduo ou mesmo o estigma (concetual) de anulação do individual. "Comunidade", no sentido que a associação entre arte e comunidade lhe vem conferir, inscreve - assim nos parece - dois movimentos relacionais de um mesmo processo artístico e técnico que se reconhece como sendo indissociável do político: acionar o poder em comum, sem deixar de ativar em cada um o poder de ser (para si e com o outro).

Na conceção comunitária dos projetos da PELE, a participação ativa no desenvolvimento de um processo estético (ou na criação de um objeto artístico) pretende-se, simultaneamente, potenciadora do coletivo (da ação de um coletivo e do coletivo em ação) e emancipadora do ser (pela consciência de si e na relação com os outros). Conforme se afirma neste excerto de uma entrevista concedida por Hugo Cruz ao jornal Público, por ocasião da publicação do livro Arte e

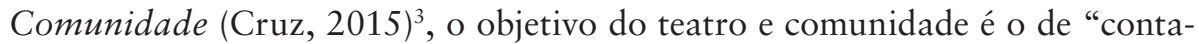
minar os outros contextos da vida das pessoas" de modo a que "elas possam perceber que se ali dizem que acham que uma cena pode ficar melhor de outra maneira, na reunião de condomínio também podem ter opinião e exprimi-la” (Cruz, cit. in. Pereira, 2015).

Cabe aqui lembrar que no seu desdobramento sociologicamente mais comum, o conceito de "comunidade" faz-nos recuar ao século XIX, à aceção de Ferdinand Tonnies (1989), com a comunidade de sangue (parentesco), de lugar (vizinhança) e de espírito (amizade). Hoje, quando o termo "comunidade" surge associado à arte ("Arte e Comunidade"), o que também está, ainda, em consideração é a ligação ao lugar enquanto condição da prática artística comunitária. Hugo Cruz (2015), ao propor-se sintetizar pontos de convergência entre tendências e desenvolvimentos da arte e comunidade muito diversos - o teatro do oprimido de Augusto Boal espalhado por vários continentes, o teatro de vizinhos (na Argentina), o teatro para o desenvolvimento (no Brasil), o teatro de liberdade como resistência cultural aos territórios ocupados (na Palestina),

3 Arte e Comunidade (2005) é uma obra com a coordenação de Hugo Cruz, onde são reunidos contributos de vários autores, investigadores e artistas (sobretudo encenadores), com conhecimentos, experiências e reflexões, em contextos diversos e com distintas tradições (Portugal, Brasil, Argentina, Holanda e Palestina) no vasto campo da arte comunitária. 
a dança na comunidade (em Portugal, da coreógrafa Madalena Victorino), a orquestra geração (também em Portugal, inspirada, no modelo El Sistema, na Venezuela) -, permite-nos, de fato, reconhecer a preponderância do lugar como uma segunda camada de sentido do termo comunidade sobretudo, enquanto figura acional dos projetos artísticos afetos ao campo da Arte e Comunidade.

Mas quais os significados com que o lugar vem configurar a dimensão comunitária destes projetos artísticos? Com o significado de aproximar a arte ao lugar ou ao contexto espácio-temporal do quotidiano das pessoas que lhe estão associadas. É neste sentido que os projetos comunitários são sobre a comunidade, porque trabalham com memórias individuais e coletivas, estórias e história relativas à vida das pessoas à escala do local e das suas especificidades (cultural, territorial, laboral, e outras). Com o significado, também, de juntar num lugar-comum, (a sala dos ensaios da orquestra ou da peça de teatro, a oficina da pintura coletiva) pessoas necessariamente diversas em vários dos aspetos configuradores das suas vidas (idade, sexo, orientação sexual, religião, e outros) que são envolvidas como coparticipantes num processo coletivo de criação artística. Com o significado, igualmente, de apresentar a arte realizada fora dos espaços convencionais, nos espaços que contextualizam e/ou que constituem matéria de criação do objeto artístico ou para o desenvolvimento do processo estético. O que também quer dizer "espaços onde se deseja que aconteçam mudanças” diminuindo assim a distância entre o imaginado e o real (Cruz, 2015: 538), ou seja, nos próprios espaços onde residem, trabalham ou estão reclusas... as pessoas-participantes dos projetos artístico-comunitários. Com o significado também de apresentar a arte realizada em espaços que por serem públicos, como as ruas, as praças, os mercados, são potencialmente espaços de cruzamento de pessoas diversas. Com o significado, ainda, de explorar a possibilidade de olhar para um lugar carregado de sentidos negativamente fixados a partir de outros pontos de vista capazes de descolar esse lugar e aqueles que o habitam das representações negativas que os diminuem.

\section{Incluir pela arte os residentes de Sucupira e Lagoa}

Num artigo do Diário do Minho de 9 de maio de 2016 intitulado "Esposende promove inclusão pela arte" (Fernandes, 2016), noticiava-se a apresentação pública do projeto AMAReMAR, ocorrida na Câmara Municipal de Esposende (CME). O acesso ao documento técnico do projeto (CME, 2015) viria confirmar o propósito divulgado: incluir pela arte os residentes de Sucupira e Lagoa, considerados pelos técnicos dos Serviços de Habitação Social e da Educação como os mais desfavorecidos do município. Conforme o seu testemunho, numa das 
várias reuniões realizadas durante a investigação ${ }^{4}$, apesar de o AMAReMAR não se fechar à generalidade da população residente em Esposende, quer a sede deste projeto quer as suas oficinas artísticas - teatro, ilustração, música e vídeo e fotografia - foram realizadas nas imediações dos dois bairros de habitação social. Em virtude da população de Sucupira e Lagoa "habitualmente não participa[r] em iniciativas locais nem frequenta[r] equipamentos municipais”, em conjunto com os agentes artísticos que dinamizaram o Projeto, os técnicos entenderam que esta localização de proximidade poderia facilitar a participação da população dos dois bairros e assim potenciar o alcance dos objetivos do projeto.

Os dados que seguidamente se apresentam têm como suporte o documento técnico do projeto (CME, 2015) bem como uma entrevista realizada aos técnicos municipais, em 2017, no decorrer do processo de investigação.

Sucupira e Lagoa (popularmente assim designados) são dois bairros de habitação social da zona sul de Esposende. De acordo com a informação fornecida em entrevista pelos técnicos, ambos os bairros têm a sua origem num processo de realojamento habitacional. O bairro de Sucupira foi construído em 1982, tendo sido habitado em 1984, “acolheu um grupo de pessoas heterogéneo", da cidade de Esposende e "oriundas das ex-colónias portuguesas", em situações habitacionais precárias. O bairro da Lagoa, construído mais tarde, entre 1889 e 1999, acolheu igualmente pessoas provenientes de várias freguesias da cidade de Esposende, vivendo em condições de precariedade habitacional, social e económica (Entrevista aos técnicos da CME).

Com base num inquérito por questionário realizado pelos técnicos da

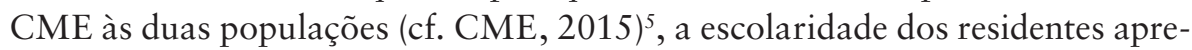
senta-se, em ambos os bairros, baixa: cerca de $10 \%$ da população é analfabeta ou tem a escolaridade básica por concluir e permanece inexpressiva a população com grau académico de nível superior. Nos dois bairros, mais de $20 \%$ dos residentes estão desempregados e a população reformada ou pensionista é significativa: cerca de $25 \%$ no bairro da Sucupira cuja população é mais envelhecida (48\% dos inquiridos têm entre os 50 e os 69 anos de idade) e $9 \%$ no bairro da Lagoa. A população ativa abrange, em cada um dos bairros, 35\% dos inquiridos, relativamente aos quais as atividades profissionais são, em ambos os casos, maioritariamente pouco qualificadas e, frequentemente, mal remuneradas, concentrando-se nos setores da hotelaria/restauração, limpeza/trabalho doméstico, construção civil, operariado fabril, assistentes operacionais e pesca. Muitos dos vínculos de trabalho são precários ou relativos a trabalho sazonal.

4 Reunião decorrida a 30 de maio de 2016, no Departamento de Ação Social da Câmara Municipal de Esposende (CME).

5 Os inquéritos foram aplicados em setembro de 2013 no bairro da Lagoa e em julho de 2014, no bairro da Sucupira. Dos 68 fogos que constituem o bairro da Lagoa, foram inquiridos residentes de 49 fogos, perfazendo um total de 79 inquiridos. Dos 88 fogos do bairro da Sucupira, foram inquiridos residentes de 48 fogos, perfazendo um total de 131 inquiridos. 
Esta situação perante o trabalho, conjugada com o baixo nível de escolaridade, deixa entrever por parte dos técnicos "uma reprodução das condições de vida entre as diversas gerações que habitam nesses bairros” (CME, 2015: 5). De entre a população mais jovem, em cada um dos bairros, cerca de 35,5\% já reprovou de ano e destes uma percentagem significativa $(25,8 \%)$ já reprovou duas vezes.

Como pudemos observar, estes dados permitem colocar em evidência a exclusão social enquanto categoria descritiva da população para a qual o projeto foi prioritariamente concebido. Noutros contextos de conhecimento - o contato direto com o coletivo (por exemplo, nas reuniões de condomínio) e o atendimento individual de apoio social -, os técnicos da CME percepcionam, contudo, a par dos aspetos de vulnerabilidade que a caracterização sociodemográfica evidencia, outros aspetos que, sendo também eles transversais à população dos dois bairros, se constituem como fatores capazes de contribuir positivamente para a "procura de soluções em momentos de grande fragilidade social e económica” (CME, 2015: 3). Assim, as trajetórias de vida ligadas à pesca e as migrações são assinaladas como características da história de vida dos moradores que "demonstram a capacidade e a competência das famílias em termos de resiliência” (CME, 2015: 3). É também, de realçar, com base nos dados do inquérito por questionário, que quando questionada a população adulta acerca das expetativas de ocupação do tempo quotidiano de lazer, a quase totalidade $(97,7 \%)$ dos inquiridos no bairro de Sucupira refere não ter atividades regulares de ocupação de tempos livres e $86,8 \%$ dos inquiridos no bairro da Lagoa "manifesta interesse em participar em projetos/ atividades de âmbito comunitário" (CME, 2015: 5). Os vários fatores que acabámos de referir, ou seja, o tempo coletivo das memórias individuais relativas a experiências de vida similares, o tempo de lazer por preencher, a disposição para ocupá-lo em atividades comunitárias e, ainda, a perceção por parte dos técnicos de haver entre os moradores a capacidade para fazer face a condições de vida adversas, parecem, pois, ter-se conjugado como condições favoráveis à participação dos residentes dos dois bairros num projeto - o AMAReMAR - que, na sua origem, isto é, do ponto de vista da CME, terá visado a inclusão dos residentes de dois bairros de habitação social (Sucupira e Lagoa) pela prática da arte em comunidade.

\section{Oficina de teatro: uma abordagem de proximidade}

De acordo com Hugo Cruz (2015: 45), na arte em comunidade, o mais importante não é o produto final mas sim a criação como motor de empoderamento: "o processo de criação encerra em si mesmo essa energia de ativação traduzida no empoderamento". Quando o Mar é mais, a peça de teatro apresentada em junho de 2017, na Marina sul de Esposende, foi o resultado de um processo 
criativo projetado pelo AMAReMAR. O seu desenvolvimento fez-se de novembro de 2016 a junho de 2017, no decurso de vários encontros semanais no contexto da oficina de teatro com a colaboração das outras oficinas que fizeram parte do projeto: música, ilustração (fig. 1), vídeo, fotografia e cenografia e figurinos.

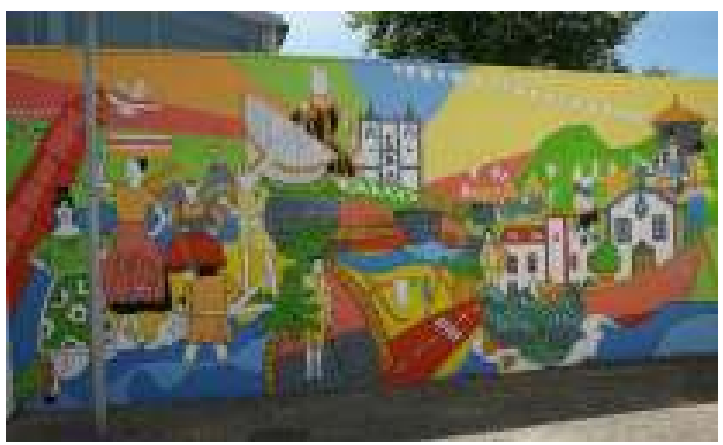

Figura 1. Vânia Silva, Mural realizado na oficina de ilustração, Bairro de Sucupira, Esposende, 9 jul. 2016

A oficina de teatro realizou-se durante nove meses (de novembro de 2016 a junho de 2017), semanalmente, num total de 34 sessões, com Susana Madeira, a formadora do grupo de participantes, e Hugo $\mathrm{Cruz}^{6}$. O grupo foi constituído por um total de 24 pessoas, residentes nos bairros de Sucupira e de Lagoa, com idades compreendidas entre os 9 e os 73 anos, dos quais 16 mulheres e raparigas/meninas e 8 homens e rapazes. Na sua generalidade, os participantes têm uma escolaridade baixa. Alguns são solteiros, outros casados, com agregados familiares de dimensão variável (de 1 a 5 elementos). Vários têm trajetórias profissionais associadas à pesca, estando alguns em situação de desemprego e outros na reforma.

A investigadora-mestranda desenvolveu observação participante no período de janeiro a junho de 2017 , tendo como contexto as sessões da oficina de teatro realizadas com o grupo de 24 pessoas. O objetivo fundamental da observação foi o de tentar compreender como é que através de um projeto de arte social se desenvolve com as pessoas participantes uma ação de abertura identitária. Ao usarmos esta expressão, "ação de abertura identitária", quisemos sob este chapéu conceptual reunir a variedade de atos, procedimentos e recursos, identificáveis no terreno da oficina, capazes de exprimir a presença dos dois movimentos relacionais do processo de arte e comunidade que atrás referimos: o movimento de acionar o poder em comum; e o movimento de 
ativar em cada um o poder de ser, desdobrado em dois sentidos, para si ou de auto-realização, e com o outro ou de partilha.

Nesta perspetiva, procedeu-se à elaboração de grelhas de observação de cada uma das sessões das oficinas de teatro. Estas viriam, todavia, a ser analiticamente subaproveitadas, pois, no decorrer da observação participante, surgiu a oportunidade de aceder ao caderno de planeamento e notas das atividades da oficina, da autoria da formadora. Tal permitiu potenciar o objetivo traçado. De facto, o desdobramento em investigadora/participante, nem sempre se coadunava espácio-temporalmente com a tarefa de proceder ao registo observacional de modo eficaz.

Por outro lado, a perceção do processo artístico de criação/formação a partir do ponto de vista interno da própria formadora era por nós reconhecida como condição assaz favorável a uma abordagem de proximidade capaz de propiciar um conhecimento mais compreensivo deste caso de arte em comunidade. O caderno (digamos de "campo") da artista/formadora acabou por se configurar no material que veio facultar à investigadora/participante o ponto de vista de quem põe em prática um projeto de arte e comunidade. A partir de dentro, do próprio contexto de interação simbólica, no caso, de criação/ formação do objeto artístico (a peça de teatro), representado no "caderno de campo" por meio dos registos das 34 sessões da oficina de teatro, acedemos, então, ao(s) sentido(s) que a formadora foi imprimindo à sua própria ação (de formação) e às leituras dos significados do agir dos outros (participantes). Do ponto de vista interpretativo das investigadoras, as várias ações em oficina constituíam-se, assim, em lances da obra a fazer (a peça de teatro), no duplo sentido que a ação adquire neste projeto de arte e comunidade, ou seja, como ação criativa do objeto artístico e enquanto ação de abertura identitária.

O uso de expressões conceptuais como "ponto de vista", "sentidos da ação", "leitura dos significados do agir dos outros", "compreensão" e “interpretação", reflete, pois, da nossa parte, uma determinada opção teórico-metodológica: abordar o objeto com ancoragem numa perspetiva sociológica de inspiração weberiana (ver Weber, 2005). Nesta investigação, é então de realçar não termos pretendido enveredar por uma abordagem vinculada a referentes teóricos e práticos do "teatro social" do qual o teatro e comunidade é uma expressão (ver Chafirovitch, 2016; Prentki e Preston, 2008; Bernardi, 2004; Schininá, 2004; Schechner e Thompson, 2004; Herven, 2001).

Tomando por base empírica o ponto de vista interno ao processo de criação/formação em arte e comunidade (se bem que, conforme esclarecido atrás, este tenha sido sociologicamente focalizado) e por intermédio do que designamos como a dimensão metódica do processo criativo (projetada e narrada no caderno de campo), estava assim (cientificamente) alcançada a condição de possibilidade objetiva para intentarmos o propósito seguinte: explicar como é que no caso do AMAReMAR se procurou mexer na identidade de enquadramento 
das pessoas participantes, com o seu ponto fixo na categoria desvalorizadora da exclusão social. Decorrente da conceção comunitária dos projetos da PELE anteriormente exposta, definimos como pressuposto que perseguir este movimento de descolagem simbólica é, pelo menos, neste caso de arte e comunidade, condição do próprio processo criativo.

\subsection{Repertório 1 - abertura identitária}

A leitura dos registos do caderno de campo, orientada para a construção de categorias explicativas da vertente metódica do processo criativo, permitiu-nos começar por identificar o que designámos por repertório 1 - recursos metódicos de abertura identitária, no interior do qual foi possível constatarmos uma série de procedimentos analiticamente remissíveis para os planos seguintes: interação, realização de si, e invenção de um lugar-comum.

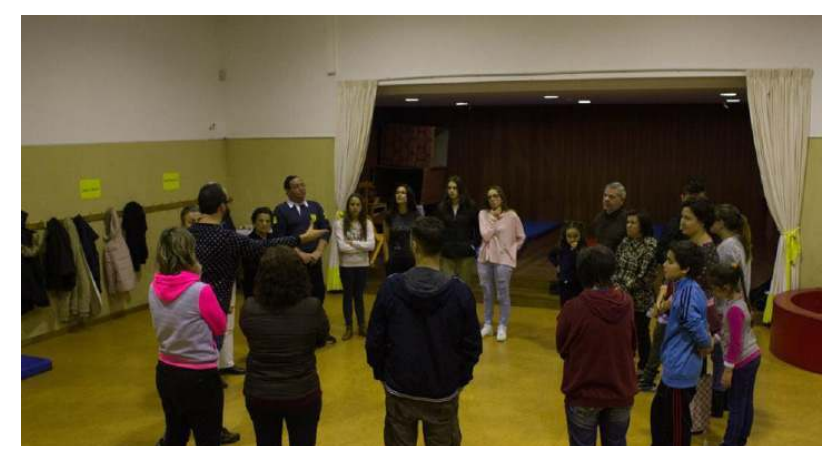

Figura 2 - Vânia Silva, Oficina de Teatro, Esposende, 7 dez. 2017

No plano da interação, é de assinalar a presença do procedimento de abertura aos outros e ao grupo (fig. 2), observado no "uso da formação do grupo em roda para uma melhor comunicação" (sessão 1, 2 nov. 2016). Igualmente, no plano da realização de si, destaca-se o procedimento de exposição/posição, patenteado no recurso à "cadeira que queima na altura da apresentação para as pessoas sentirem que têm de entrar na dinâmica do jogo, deixando a timidez ou a falta de iniciativa em avançar, assim como os mais faladores, treinarem a capacidade de síntese em comunicar uma informação ou ideia" (ibidem). Por último, no plano da invenção de um lugar-comum, de modo a despoletar uma dinâmica coletiva, procede-se numa dupla direção, trabalhar a consciência de grupo e a consciência de criação do objeto artístico, relativamente às quais se recorre ao "uso do papel de cenário numa parede e registo do que se vai encontrando ao longo da sessão, para visualmente, organizar ideias e pensamentos 
e todos usufruírem da sensação de crescimento e desenvolvimento de algo" (ibidem).

A importância dada ao trabalho de configuração da consciência de grupo, entre outros exemplos, está também presente no recurso a um brainstorming explicitamente direcionado para as questões "O que é estar em Grupo" e "O que é trabalhar em grupo?” através das quais a formadora interpela os participantes, registando destes as seguintes re-ações: "colectividade"; "interagir"; "confiança”; "entreajuda”; "união"; "concentração"; "entrega”; "feliz"; "comunicar”; "espírito de equipa”; "pertença”; "divertimento”; "partilha” (sessão 5, 30 nov. 2016). A incidência da ação da formadora na reflexividade é de igual modo observada no questionamento, junto dos participantes, da prática dos diversos jogos aos quais vai recorrendo ao longo de sucessivas e progressivas sessões, explicitando, sempre, os vários procedimentos que motivam os jogos bem como os atos que, nas dimensões física e mental, lhes são inerentes.

Assim: o "pequeno aquecimento das articulações" é "para irmos conhecendo a que partes do corpo é que devemos dar primazia num aquecimento"; o "Gato e rato" e o "Lobo e ovelhas" são para "aquecer, descontrair, trocar de papel, treinar a rápida capacidade física e mental”; o Zip Zap Boing com palavras e sem palavras" é para o "ritmo; olhar claro; implicação de todo o corpo a passar a energia; rápida resposta física e mental; concentração"; os jogos com objetos são "para descobrir diferentes formas de transportar e entregar um objeto, treinar o olhar (sessão 5, 30 nov. 2016). Assim: “Levantar e baixar os braços” é (para além da incidência na capacidade de reação física e mental) destinado à "concentração", à "observação do outro", a "trabalhar a calma"; a "Troca de objetos, troca de gestos e troca de nome" visa (entre outros atos e/ou resultados já mencionados) a "atenção ao outro" a "memória auditiva e visual”, a "objetividade", a "eficácia” e a "clareza na passagem da mensagem"; "Andar pelo espaço com diferentes ações” pretende (de entre outros resultados atrás referidos) "acalmar a ansiedade"; "Em roda pelo espaço, entrega de objetos" destina-se a "descobrir diferentes formas de transportar e entregar um objeto", a "treinar o olhar", ao "cuidado e eficácia na entrega do objeto", à "objetividade, decisão, postura disponível e pronta para a ação", à execução de "movimentos claros e desenhados" (sessão 6, 7 dez. 2016).

\subsection{Repertório 2 - criação do objeto artístico}

Os registos constantes do caderno de campo levaram-nos, também, a identificar o que designámos por repertório 2 - recursos metódicos de criação do objeto artístico. Tal repertório reenvia-nos diretamente para o movimento de acionar o poder em comum. Este é, por seu turno, indissociável da ativação do poder de ser, nos dois sentidos atrás considerados: para si (ou de auto-realização) e com o outro (ou de partilha). 
A invenção de um lugar-comum, afinal, o próprio objeto artístico, é posta em movimento a partir do contributo de cada um dos participantes para um projeto que se define como coletivo. As "visita[s] guiada[s] a lugares de Esposende em que os participantes são os guias" configuram-se como um procedimento de "aproximação ao espaço e às potencialidades do próprio espaço e das histórias". Essa aproximação é feita "através das escolhas" dos participantes do grupo 7 uma rua do bairro de Sucupira, escolha da Sara e da Fátima, o armazém do Eliano, escolha do Eliano e do Martinho, a rua que divide entre o Norte e o Sul e o lugar onde jogavam à bola, outras escolhas do Eliano e do Martinho, a rampa junto ao cais, escolha da Eugénia, o estaleiro, escolha da Margarida (sessão 2, 9 nov. 2016).

Os seus "olhares" e os seus "conhecimentos" (sessão 2, 9 nov. 2016) são convocados e registados:

(...) ali [numa rua no Bairro de Sucupira] passava um rigueiro, existiam tanques de lavar a roupa, as crianças tinham como brincadeira 'apanhar colhercinhas' (ovas de sapos) (...) no rigueiro também se faziam barquinhos com cascas de pinheiro (...) batiam-se as redes na água para tirar o lodo (...), de Viana vinha o material para fazer as redes, era o sisal (...) (cit. Sameiro e Fernanda in sessão 2, 9 nov. 2016).

Por intermédio dessas incursões espácio-temporais, agenciadas pelos participantes, são trazidos "lugares", "sons", “imagens", "recordações" que, também nas palavras da formadora, "servirão como inspiração para o espetáculo" (sessão 2, 9 nov. 2016):

(...) quando éramos canalha, aqui [na Travessa dos Pescadores] era muito escuro e a gente benzia-se (...) (cit. Eliano e Martinho in sessão 4, 23 nov. 2016).

(...) ali [no estaleiro] morreu uma senhora a cantar, estava cheia de fome (...) (cit. Margarida in sessão 4, 23 nov. 2016).

(...) este local [onde jogavam à bola] é dos mais emblemáticos (...), ali eram os estaleiros e ao lado os varais, tipo baliza de futebol (...) O Martinho era o chefe do gang do Sul...espada de pau...inventou um arco de flecha com um guarda-chuva (...) Norte contra o Sul em correrias, sticks com troços de couves (...) (cit. Eliano e Martinho in sessão 4, 23 nov. 2016).

7 Para garantia de confidencialidade da informação relativa aos participantes, substituímos os seus nomes por nomes fictícios. 
Estes e muitos outros registos do que podemos designar por um banco simbólico de recursos virão a transformar-se em materiais para a construção do objeto artístico. Noutras sessões, os participantes trazem objetos e/ou fotografias que levam a descobrir histórias suas e relacionadas com Esposende e as “suas gentes” e que serão lançados, em ensaios seguintes, na experimentação de composições e de materiais cenográficos (sons, cores, figurinos) a serem incorporados na peça de teatro como criação coletiva. De entre os vários registos, vejamos, de seguida, alguns exemplos.

As agulhas de madeira trazidas pelo Eliano vão suscitar a ideia de executar com os movimentos de coser as redes uma dança de peixes a finalizarem num cardume (ref. sessão 10, 25 jan. 2017).

A gamela e a rodilha, trazidas pela Mariana (fig. 3), outrora usadas para ir ao cais buscar o peixe, virão a ser usadas na cena do remate de peixes cujos nomes são distribuídos pelo cardume de mulheres (fig. 6). Atravessando o espaço do palco com gamelas à cabeça e tendo por leiloeiro o maestro do Coro Ars Vocalis, uma das entidades locais que foi chamada a colaborar no processo artístico, cada uma das mulheres apregoará o seu peixe: sardinha, faneca, lampreia, raia, carapau, badejo, peixe-rosa, taínha, peixe sapo (tamboril), cavala, polvo, solha (ref. sessão 11, 1 fev. 2017).

As fotografias da Tasca da Tia Nazaré (fig. 4), por "todos" lembrada "com um sorriso", trazidas pelo José que em pequenino ia "lá buscar meio quartilho de vinho", induzirão a cena da criança a trautear "um quartilho de vinho branco de pipa", "tinto?", "branco?"," tinto?" branco" (ref. sessão 11, 1 fev. 2017).

O búzio, também trazido pelo José, que o Eliano associa ao "som do batimento do mar”, virá a suscitar, no espetáculo, o uso de búzios (fig. 5), em ambiente de nevoeiro, avisando que "os barcos estão a entrar na barra" (ref. sessão 10, 25 jan. 2017).

A “Canção do Remar” com o seu refrão “Oh Remo, remo”, trazida pelo Eliano, virá a ser entoada no espetáculo como "som memória” (ref. sessão 10, 25 de jan. 2017) convocado a cada passagem dos remadores do Clube Náutico de Fão como atuante temporal.

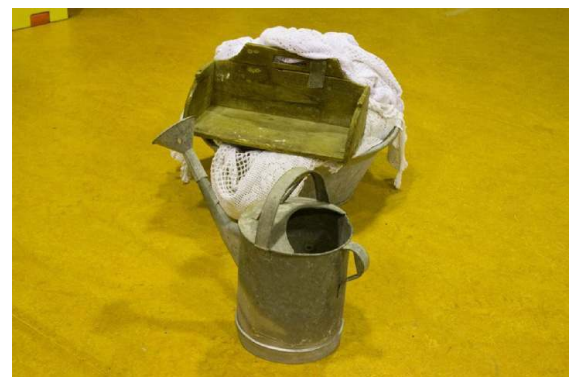

Fig. 3 - Vânia Silva, Oficina de Teatro, Esposende,13 setembro 2017.

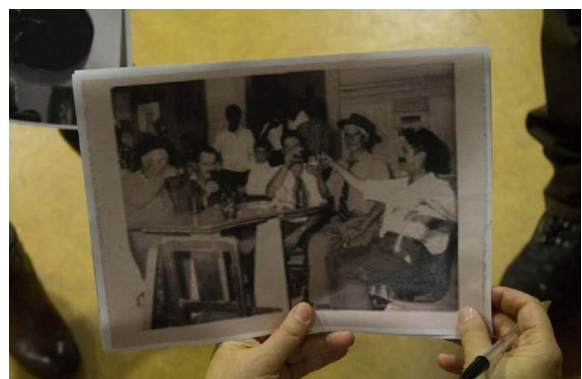

Fig. 4 - Vânia Silva, Oficina de Teatro, Esposende, 1 fev. 2017 


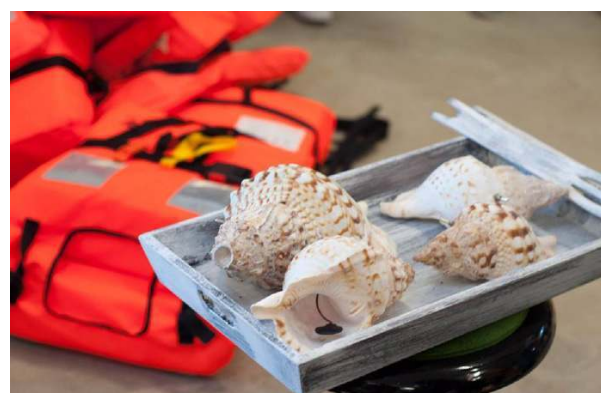

Fig. 5- Vânia Silva, Oficina de Teatro, Esposende, 2 jun. 2017

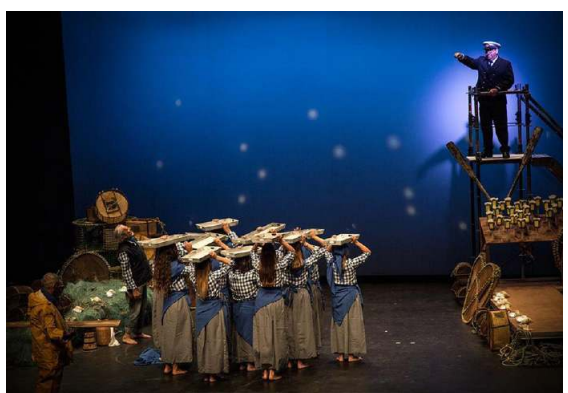

Fig. 6- Vânia Silva, Quando o Mar é mais, Teatro Carlos Alberto, Porto, 23 set. 2017

Mas Esposende não é apenas abordada pelo prisma de um lugar feito de lugares que se relembram através do filtro das memórias alicerçadas nas vivências passadas e mediante as escolhas e as recolhas dos participantes dos Bairros de Lagoa e Sucupira. Na sinopse do espetáculo, lê-se que: Quando o Mar é mais "é a construção colectiva de um resultado artístico e de reflexão sobre o lugar em que se vive, como se vive e como se quer viver" (Cruz e Madeira, 2017). De facto, no Relatório Trimestral da Oficina de Teatro (de novembro 2016 a janeiro 2017), observa-se que este objeto artístico foi, também, pensado como um meio de se "falar" do "presente de um lugar (Esposende) a partir dos corpos, vozes, e vontades dos próprios habitantes /protagonistas [desse] mesmo lugar" (Cruz e Madeira, 2017). Mesmo que sobriamente, o processo artístico funcionou como transportador de alguns dos "desejos" dos seus participantes "para o futuro de Esposende" (sessão 14, 22 fev. 2017). Assim, quando interpelados acerca da "dimensão futura do espetáculo", o mesmo é dizer, a dimensão futura de Esposende, confirmam-se necessidades - "mais emprego/trabalho", "centro de saúde centralizado", "sala de concertos/multiusos", "atividades infantis/desportivas e recreativas" - e soltam-se vontades - shopping, discoteca, mais dança, passeios de barco, praias com conchas... -, umas e outras exprimindo a preponderância do lugar como figura acional na prática artística comunitária (sessão 4, 22 fev. 2017), desta feita, num dos seus múltiplos sentidos, o de dar voz aos habitantes de um lugar desvalorizado.

Em sessões posteriores, na composição dos vários tipos de personagens e cenas, textos, canções, refrões, tudo é experimentado, discutido e decidido em equipa. Assim, por exemplo: para a cena da praia, é lançado "um desafio a algumas meninas para criarem uma dança muito simples de $15^{\prime \prime}$ " (sessão 18, 22, mar. 2017); para a cena dos veraneantes é feito "um pedido de sugestões de músicas" (sessão 17, 15 mar, 2017); o texto sobre o naufrágio é trazido pelo Eliano, o texto do fado vadio é da autoria da Eugénia (sessão 15, 1 mar, 2017). 


\subsection{Repertório 3 - uma ética do reconhecimento}

Ao sexto mês de emersão nos ensaios da oficina de teatro, participou-se como investigadora-atriz na peça Quando o Mar é Mais que foi levada à cena, a 3 de junho, ao ar livre, na Marina Sul de Esposende (fig. 7). Nos meses de agosto e setembro, esse papel prolongar-se-ia na condição de participante nos ensaios de adaptação da peça à sua apresentação a 23 de setembro, na sala do Teatro Carlos Alberto (fig. 8), no contexto do Festival MEXE - IV Encontro Internacional de Arte e Comunidade, coordenado por Hugo Cruz e realizado no Porto (de 18 a 24 de setembro).
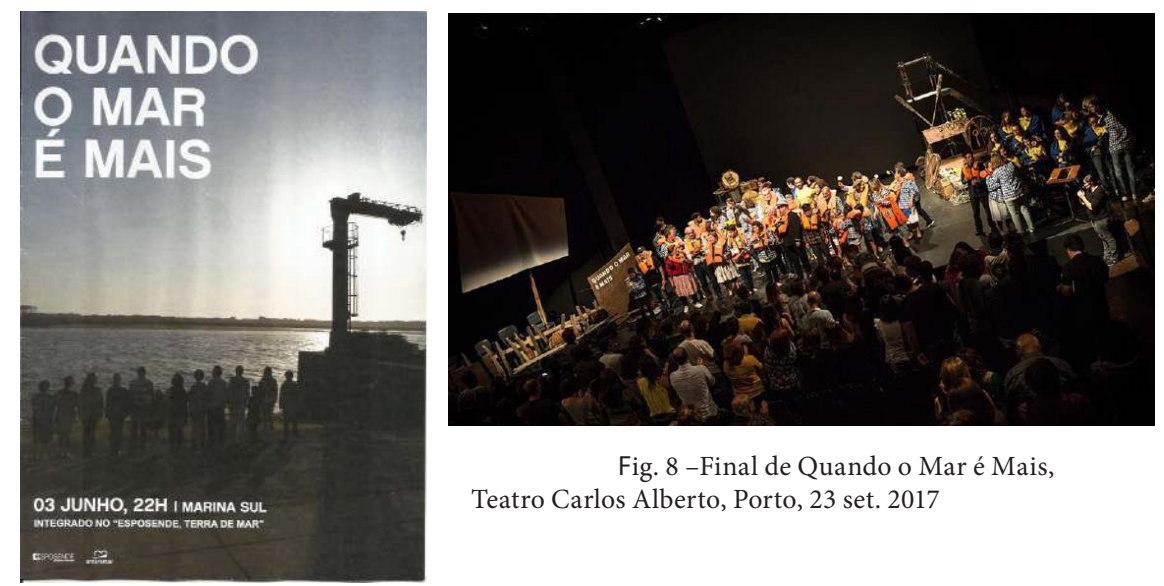

Fig. 8 -Final de Quando o Mar é Mais,

Teatro Carlos Alberto, Porto, 23 set. 2017

Fig. 7 - Folha de sala de Quando o Mar é Mais,

Marina Sul, Esposende, 3 jun. 2017

A produção e divulgação da peça implicaram necessariamente o acionar de meios técnicos e logísticos relativamente aos quais nos foi dado apreender, tal como no processo criativo (acima abordado), sinais da presença do que podemos designar por repertório 3 - recursos metódicos de uma ética do reconhecimento. Neste repertório, incluímos, então, o que denominamos de três ordens de reconhecimento.

$A$ primeira ordem de reconhecimento tem como aglutinador a autoridade que os artistas do projeto (a formadora e o coordenador) conferem aos participantes, ao deslocá-los, em declinações várias, para o lugar de participantes ativos na criação de um objeto artístico (a peça de teatro), seja por intermédio dos jogos de ativação de si perante os outros e de si para si - expor-se, tomar posição, refletir -, seja pelo protagonismo que lhes é atribuído, quer enquanto guias das visitas do grupo a lugares de Esposende, quer como coletores/construtores de um banco simbólico de recursos para a concepção do objeto artístico e, ainda, como intérpretes/atores das personagens atuantes na peça (mesmo tratando-se de papéis simples) e como coautores ou avaliadores de textos e canções. Exemplos deste último caso são: a escolha por parte dos 
participantes do título a dar à peça (Quando o Mar é mais), bem como a escolha do nome a dar ao grupo de teatro (Triumph'arte - Grupo de Teatro Comunitário de Esposende); e a aprovação em grupo da sinopse do espetáculo a constar da ficha artística e técnica de divulgação pública.

A segunda ordem de reconhecimento é relativa a entidades, pessoas e grupos que compondo o tecido social local são contatados e/ou convidados pelos artistas do projeto para aquisição de conhecimentos específicos, colaboração no trabalho de conceção ou realização da peça, pelo seu espólio, capital simbólico acumulado ou competência prática num dado domínio. A título de alguns exemplos, considere-se os seguintes: as visitas ao Museu Marítimo, à Estação de Socorros a Náufragos, ao Estaleiro, e ao Atelier Fernando Rosário; as conversas com distintas personalidades detentoras de informação privilegiada; a presença da Associação de Pescadores Profissionais do Concelho de Esposende no espetáculo, ou a participação dos nadadores-salvadores, dos remadores do Clube Náutico de Fão, ou do Coro Ars Vocalis, convidados que foram a colaborar no espetáculo, à semelhança de outros casos expressivos da intensificação do trabalho colaborativo nas práticas artísticas, designadamente, no contexto português (ver, por exemplo, Mora, 2017; Borges, 2018).

Por último, há que considerar uma terceira ordem de reconhecimento composta por um conjunto diverso de meios tendo como denominador comum o movimento de deslocação física e simbólica dos protagonistas da peça dos ensaios da oficina de teatro, enquanto espaço de transição (considerados os bairros como ponto de partida do projeto, o que quer dizer, a exclusão social como categoria de enquadramento), para o espetáculo como espaço público de reconhecimento. Disso são exemplos a inclusão dos nomes de vários dos participantes ao lado de nomes como Sophia de Mello Breyner Andresen e Ernest Hemingway enquanto autores dos textos na ficha do espetáculo, e a apresentação da peça num espaço de arte convencional e com uma carga simbólica central como é o caso do Teatro Carlos Alberto.

\section{Nota final}

Através de uma abordagem de proximidade ao processo de criação em arte e comunidade, desenvolvido no AMAReMAR procurámos mostrar que este projeto teve o intuito de potenciar nos seus participantes vontade de ser (ver Honneth, 2011: 237) nos sentidos múltiplos que a esta asserção conferimos: acionar o poder em comum, ativar em cada um o poder de ser para si e com o outro e saber-se reconbecido. O caderno de campo da formadora-artista foi revelador de uma ação de abertura identitária que vimos ter sido metodicamente agenciada, desde as sessões das oficinas de teatro até às apresentações da peça. Foi por deslocação ascendente de um lugar desvalorizado (o de residente 
em bairro de habitação social) para sucessivos contextos interativos e reflexivos de valorização pessoal, social e cultural (dos jogos entre pares na oficina de teatro, ao acesso ao Teatro Carlos Alberto como lugar normativo da arte) que se operou um movimento de descolagem simbólica da categoria desvalorizadora da exclusão.

A confirmação desta experiência é assinalável nos testemunhos que, na fase final da observação participante, recolhemos em conversa informal com 11 (maioritariamente mulheres) dos 24 participantes no grupo. Eis alguns desses depoimentos:

Senti que um bocadinho do que eu disse era sempre importante. (...) Eu ficava motivada para continuar o resto do dia só para ter teatro (...). Eu nunca pensava que ia ficar tão próxima de pessoas muitos mais velhas que eu que não fossem da minha família, ou crianças (...). Nós passamos na rua e parece mesmo que somos uma família. (Cristina)

Eu tenho pânico de falar em público (...) recuso-me mesmo mas com ela [a formadora] eu aceitei o desafio porque eu senti que ela acreditou em mim, porque ela merecia. (Carla)

É através deste projeto que as pessoas conseguem deixar sair cá para fora o que realmente está escondido (...). Nós ensaiávamos e muitas vezes éramos criticados porque muitas pessoas acreditavam que nós nunca íamos fazer nada (...) e no entanto, quando nós apresentámos houve pessoas que choraram, houve pessoas que nos deram os parabéns. (Clotilde)

Eles cativam uma pessoa de tal maneira que nós acabávamos por não sentir vergonha de nada (...). Não estava à espera que a união fosse tão grande. (...) nem que seja um minuto do dia, eu me lembro do teatro e lembro deste grupo (...). Aqui na comunidade não é fácil uma pessoa se abrir muito para a comunidade, acho que é muito julgada e isto é uma forma de mostrar que conseguimos. (Aida)

Importa, por fim, anotar aqui um outro facto elucidativo desta experiência de descolagem simbólica. Desta vez com um duplo sentido, pois que a mudança de lugar não foi apenas dos participantes no projeto. O facto é que houve também uma relativização do próprio contexto académico, resultante da vontade de termos querido provocar a sua abertura a um público outro. Decidimos (orientadora e mestranda) entregar a cada um dos 24 elementos do grupo, pessoalmente, mas formalmente (por carta com o timbre do Instituto de Ciências Sociais da

Universidade do Minho), o convite para assistir às provas de mestrado 
em Sociologia da investigadora participante na oficina de teatro. Foi visivel o interesse e a satisfação de todos quantos estiveram lá, simultaneamente, na condição de participantes no projeto e na condição de público da apresentação/discussão da tese sobre o projeto. No início das provas tornámos pública a sua presença, ao lado dos muitos estudantes que também faziam parte da assistência. Enquanto orientadora, foi tomada a decisão de dirigir parte da intervenção diretamente àqueles que havíamos convidado. Essa decisão foi facilitada por ser, então, também coordenadora do mestrado em Sociologia.

Estavam deste modo reunidas as condições para o espaço normativo da sala de atos do Instituto de Ciências Sociais se tornar, ainda que provisoriamente, no prolongamento de uma convicção que este estudo sobre o projeto de arte social AMAReMAR vem firmar: a mais-valia individual e coletiva das criações artísticas com grupos normativamente identificados como sendo portadores de um qualquer tipo de fragilidade social é a de mexer na identidade dos participantes e significa, mesmo que passageiramente, demover a pessoa de um círculo íntimo, e mais ou menos parcial, de não-reconhecimento de si.

\section{Referências bibliográficas}

ALMEIDA, João Ferreira de et al (1992), Exclusão social. Factores e tipos de pobreza em Portugal, Lisboa, Celta Editora.

BERNARDI, Claudio (2004) Il teatro sociale, Roma, Carocci.

BORGES, Vera (2018), "Arte colaborativa: uma observação localizada dos teatros e dos seus públicos”, Etnográfica, junho de 2018, vol. 22 (2), pp. 453-476.

CHAFIROVITCH, Cristina Russo (2016), Teatro social. Criação artística, acção e performance na comunidade, Lisboa, Esfera do Caos Editores.

CME, Câmara Municipal de Esposende, (2015), AMAReMAR, Há ir e Voltar, CME, Esposende, 22 págs.

COSTA, Alfredo Bruto da (1998), Exclusões sociais, Lisboa, Gradiva/Fundação Mário Soares.

CRUZ, Hugo, MADEIRA, Susana (dir.) (2017), Quando o Mar é mais, Ficha artística e técnica. Esposende, CME / AMAReMAR.

CRUZ, Hugo (coord.) (2015), Arte e Comunidade, Lisboa, Fundação Calouste Gulbenkian.

DIOGO, Fernando, CASTRO, Alexandra, PERISTA, Pedro (2015) (org.), Pobreza e exclusão social em Portugal. Contextos, transformações e estudos, V. N. Famalicão, Edições Húmus.

ERVEN, Eugene Van (2001), Community Theatre: global perspectives, London, Routledge. FERNANDES, Joaquim Martins (2016), "Esposende promove inclusão pela arte”. In Diário do Minho. 9 de Maio de 2016, p. 9.

FORTUNA, Carlos (coord.) (2014), Cultura, formação e cidadania: Relatório final, CES Centro de Estudos Sociais.

GUETZKOW, Joshua (2002), "How the arts impacts communities: an introduction to the literature on arts impact studies", Taking the measure of culture Conference, Working paper séries, 20.

GULBENKIAN, Fundação Calouste (2017a), “PARTIS, Práticas artísticas para a inclusão social”, [Online], disponível em: https://gulbenkian.pt/project/partis/ [consultado em: 25.07.2017). 
GULBENKIAN, Fundação Calouste (2017b), "PGCIS, Programa Coesão e Integração Social”, [Online], disponível em: https:/gulbenkian.pt/programas/programa-gulbenkian-coesao-e-integracao-social/ [consultado em: 26.07.2017).

HONNETH, Axel (2011), Luta pelo reconhecimento. Para uma gramática moral dos conflitos sociais, Lisboa, Edições 70.

JERMYN, Helen (2005), The art of inclusion, Research Report, England, July.

JERMYN, Helen (2001), The arts and social exclusion: a Review prepared for the Arts Council of England.

LAMOUREUX, Ève (2010), “Les arts communautaires: es pratiques de résistance artistique interpeliées parla souffrance sociale”, Amnis, Revue de civilisation contemporaine Europes/ Amériques, $\mathrm{n}^{\circ}$ 9, pp, 1-12 [Online], disponível em http://journals.openedition.org/amnis/314 [consultado em 21.07. 2017).

MATARASSO, François (2017), “Keeping the art in focus” [Online], disponível em: https://arestlessart.com/ [consultado em: 17.04. 2017]

MATARASSO, François (1997), Use or ornament? The social impact of participation in the arts, Stroud, Comedia.

MEF, Movimento de Expressão Fotográfica [Online], disponível em: http://www.mef.pt/mef/ [consultado em: 25.07.2017).

MORA, Teresa (2017), "House on Fire: um caso de arte política e colaborativa”, Comunicação e Sociedade, vol. 31, pp. 133-147 [Online], disponível em: http://revistacomsoc.pt/index.php/ comsoc/issue/view/218 [consultado em 26.07.2017).

PARTIS, Práticas artísticas para a inclusão social [Online], disponível em: https://gulbenkian.pt/ project/partis/ [consultado em: 25.07.2017).

PELE, Espaço de Contacto Cultural e Social (2017) [Online], disponível em: https://www.apele. org/ [consultado em: 24.07.2017].

PRENTKI, Tim, PRESTON, Sheila (ed.) (2008), The Applied Theatre Reader, London, Routledge.

PEREIRA, Ana Cristina (2015), "Arte e comunidade: o seu ADN é feito de encontros improváveis”. In Público, 18 de Julho de 2015 [Online], disponível em: https://www.publico. pt/2015/07/18/sociedade/noticia/arte-e-comunidade-1702383 [consultado em: 20.01. 2017]

SCHECHNER, Richard e THOMPSON, James (2004), "Why 'Social theatre' ?”, The Drama Review, 48 (3), pp. 11-16.

SCHININÀ, Guglielmo (2004), "Here we are: Social theatre and some open questions about its developments”, The Theatre Drama Review, 48 (3), pp. 17-31.

TILLER, Chrissie (2014), Participatory performimg arts: a litterature review, Lisboa, Fundação Calouste Gulbenkian/ UK Branch.

TONNIES, Ferdinand (1989), "Comunidade e sociedade", in CRUZ, Manuel Braga da (org.), Teorias Sociológicas, I Vol. Os fundadores e os clássicos (Antologia de Textos), Lisboa, Fundação Calouste Gulbenkian, pp. 511-517.

WEBER, Max (2005), Conceitos sociológicos fundamentais, Lisboa, Edições 70, pp. 21-45. 